\title{
Caso de estudio: el default del Ecuador 2008-2009.
}

Case study: the default of Ecuador 2008-2009

\author{
Gonzalo Andrés Rodríguez Arrieta. ${ }^{1}$, Halder Yandry Loor Zambrano. ${ }^{2}$, \& Walter Ivan \\ Navas Bayona. ${ }^{3}$
}

Recibido: 18-10-2018 / Revisado: 19-11-208 /Aceptado: 29-12-2018/ Publicado: 05-01-2019

\begin{abstract}
.
DOI: https://doi.org/10.33262/cienciadigital.v3i1.350

The difficulty in paying the debt acquired by a given country with investors and other multilateral credit institutions at an external level is a common phenomenon in Latin America, however, it must be emphasized that some countries in Europe have not escaped this situation either. all during the last decade, reason why the present case study intends to provide an economic analysis that establishes the way in which the economic authorities of Ecuador, during the first presidential term of Rafael Correa (2007-2009), determined that the restructuring of the Ecuadorian debt had been badly negotiated by previous governments, considering certain segments of the national external debt as "illegitimate", unilaterally, after an audit carried out by the Public Credit Integral Audit Commission (commission created in June 2007 by former president Rafael Correa to analyze the amounts contracted by the Est Ecuadorian between 1976 and 2006), whose results were presented in November 2008, therefore declaring the moratorium on payment (cessation of payments) of the interests of the Global 2012 and Global 2030 Bonds in December 2008, considering that they were hired or renegotiated in an irregular manner and with a strong prejudice for the country. It will be a subject of study, provide answers to the following questions: how was such a high level of external debt reached? What was the way to rescue the debt classified as illegitimate?, and what happened after this process?.
\end{abstract}

Keywords: Case, Case Study, Payments, Debts, Country Default of Ecuador.

\footnotetext{
${ }^{1}$ Universidad Laica Eloy Alfaro de Manabí, Manabí Ecuador, andres.rodriguez@uleam.edu.ec

${ }^{2}$ Universidad Técnica de Manabí, Manabí; Ecuador, hloor@utm.edu.ec

${ }^{3}$ Universidad San Gregorio de Portoviejo, Portoviejo Ecuador, winavas@sangregorio.edu.ec
} 


\section{Resumen.}

La dificultad en el pago de la deuda adquirida por un determinado país con inversores y demás organismos multilaterales de crédito a nivel externo es un fenómeno habitual en Latinoamérica, sin embargo, hay que enfatizar que de ésta situación tampoco han escapado algunos países de Europa, sobre todo durante la última década, razón por la que el presente caso de estudio pretende proporcionar un análisis económico que establezca la forma como las autoridades económicas del Ecuador, durante el primer período presidencial de Rafael Correa (2007-2009), determinaron que la restructuración de la deuda ecuatoriana había sido mal negociada por gobiernos anteriores, considerando como "ilegítimos" ciertos segmentos de la deuda externa nacional, de manera unilateral, luego de una auditoría efectuada por la Comisión de Auditoría Integral del Crédito Público (comisión creada en junio de 2007 por el ex presidente Rafael Correa para analizar los montos contraídos por el Estado ecuatoriano entre 1976 y 2006), cuyos resultados fueron presentados en noviembre de 2008, declarando por consiguiente la moratoria al pago (cesación de pagos) de los intereses de los Bonos Global 2012 y Global 2030 en diciembre de 2008, por considerar que fueron contratados o renegociados de forma irregular y con un fuerte perjuicio para el país. Será materia de estudio, brindar respuestas a las siguientes interrogantes: ¿cómo se llegó a tan elevado nivel de endeudamiento externo?, ¿cuál fue la forma de rescate de la deuda catalogada como ilegítima?, y ¿qué sucedió luego de este proceso?

Palabras claves: Caso, Caso de Estudio, Pagos, Deudas, País Default del Ecuador.

\section{Introducción.}

\section{Presentación del problema:}

Latinoamérica se ha caracterizado por etapas similares y de rápido contagio en cada uno de los sucesos políticos, económicos, financieros y sociales en los que la región se ha visto envuelta; es más evidente aún este suceder concatenado, si se aísla a Sudamérica del resto de Latinoamérica. Se observa en el objeto de este trabajo que concierne a la deuda externa del estado, la similitud de capitales que llegan y se van de la región, los procesos de renegociación con organismos multilaterales de crédito, la influencia de países en ciertas economías emergentes, las crisis provocadas, y el padecimiento de los ciudadanos ante el mal manejo de la economía de un país (Pettiná, 2014). Se ve reflejado el efecto generalizado, por ejemplo, en el periodo 1975 - 1980 (época de gobiernos militares en muchos países) a través de CEPAL (2014) en el cuadro 1. El aumento de todos los indices de endeudamiento publico y privado (sólo exceptuando la deuda privada en Panamá en ese período de análisis), considerado desde el punto de vista de Pettiná como el periodo de explosión del endeudamiento de la región, y a partir del cual se realizaron reestructuraciones de deudas 


\section{Sigital}

ISSN: 2602-8085

WWW.cienciadigital.org

Vol. 3, $\mathrm{N}^{\circ}$ 1, p. 481-494, enero - marzo, 2019

como el más conocido en la región: "Plan Brady", plan diseñado en 1989 por Nicholas Brady, secretario del tesoro de Estados Unidos, por aquel entonces, en el marco de la crisis de la deuda latinoamericana, cuya estrategia adoptada sugería la emisión de bonos para renegociar el capital e intereses vencidos con la banca internacional y se constituyó como un mecanismo para la reducción de la deuda así como de garantía para el pago de la misma a los acrredores.

La problemática de la deuda externa que se aborda en este documento toma el caso de Ecuador, como país de la región, enfocado desde el punto de vista de su creciente deuda externa, default (suspensión de pagos) unilateral y recuperación de deuda. La particularidad del mismo radica en cómo Ecuador realizó un rescate de deuda repudiada unilateralmente por ilegítima y cuál fue el mecanismo que utilizó para poder recuperar la deuda externa que apretaba las cuentas del estado, y que por décadas había perjudicado su accionar presupuestario debido al pago por el servicio de la deuda adquirida.

Cuadro 1: Endeudamiento en Latinoamérica 1975-1980

\begin{tabular}{|c|c|c|c|c|c|c|c|c|c|}
\hline & \multicolumn{2}{|c|}{$\begin{array}{c}\text { Deuda pública } \\
\text { externa } \\
\text { desembolsada* }\end{array}$} & \multicolumn{2}{|c|}{$\begin{array}{l}\text { Deuda externa } \\
\text { privada }{ }^{\circ}\end{array}$} & \multicolumn{2}{|c|}{$\begin{array}{c}\text { Deuda externa } \\
\text { total }\end{array}$} & \multirow{2}{*}{$\begin{array}{c}\text { Variación } \\
\text { porcentual } \\
\text { de la } \\
\text { deuda } \\
\text { externa } \\
\text { total } \\
1975-1980\end{array}$} & \multicolumn{2}{|c|}{$\begin{array}{c}\text { Contribución } \\
\text { porcentual al } \\
\text { aumento de la } \\
\text { deuda } 1975-1980\end{array}$} \\
\hline & 1975 & 1980 & 1975 & 1980 & 1975 & 1980 & & Privada & Pública \\
\hline Argentina & 3023 & 14460 & 3003 & 13000 & 6026 & 27460 & 355,7 & 46,6 & 53,4 \\
\hline $\begin{array}{l}\text { Bolivia (Estado } \\
\text { Plurinacional de) }\end{array}$ & 797 & 2100 & 75 & 415 & 872 & 2515 & 188,4 & 20,7 & 79,3 \\
\hline Brasil & 13618 & 38770 & 7167 & 18517 & 20785 & 57287 & 175,6 & 31,1 & 68,9 \\
\hline Colombia & 2348 & 3980 & 1224 & 3438 & 3572 & 7418 & 107,7 & 57,6 & 42,4 \\
\hline Costa Rica & 421 & 1580 & 242 & 697 & 663 & 2277 & 243,4 & 28,2 & 71,8 \\
\hline Chile & 3731 & 4720 & 728 & 4950 & 4459 & 9670 & 116,9 & 81,0 & 19,0 \\
\hline Ecuador & 457 & 2910 & 126 & 1941 & 583 & 4851 & 732,1 & 42,5 & 57,5 \\
\hline El Salvador & 196 & 470 & 195 & 330 & 391 & 800 & 104,6 & 33,0 & 67,0 \\
\hline Guatemala & 164 & 620 & 150 & 524 & 314 & 1144 & 264,3 & 45,1 & 54,9 \\
\hline Haití & 57 & 230 & 22 & 46 & 79 & 276 & 249,4 & 12,2 & 87,8 \\
\hline Honduras & 264 & 1110 & 167 & 330 & 431 & 1440 & 234,1 & 16,2 & 83,8 \\
\hline México & 11533 & 32730 & 5732 & 17323 & 17265 & 50053 & 189,9 & 35,4 & 64,6 \\
\hline Nicaragua & 595 & 1290 & 140 & 370 & 735 & 1660 & 125,9 & 24,9 & 75,1 \\
\hline Panamá & 774 & 2320 & 413 & 355 & 1187 & 2675 & 125,4 & $-3,9$ & 103,9 \\
\hline Paraguay & 188 & 540 & 50 & 328 & 238 & 868 & 264,7 & 44,1 & 55,9 \\
\hline Perú & 2980 & 6730 & 1086 & 1768 & 4066 & 8498 & 109,0 & 15,4 & 84,6 \\
\hline $\begin{array}{l}\text { República } \\
\text { Dominicana }\end{array}$ & 410 & 910 & 96 & 511 & 506 & 1421 & 180,8 & 45,4 & 54,6 \\
\hline Uruguay & 617 & 1170 & 194 & 241 & 811 & 1411 & 74,0 & 7,8 & 92,2 \\
\hline $\begin{array}{l}\text { Venezuela } \\
\text { (República } \\
\text { Bolivariana de) }\end{array}$ & 1262 & 11570 & 3066 & 15412 & 4328 & 26982 & 523,4 & 54,5 & 45,5 \\
\hline América Latina & 43435 & 128210 & 23876 & 80496 & 67311 & 208706 & 210,1 & 40,0 & 60,0 \\
\hline
\end{tabular}

Fuente: CEPAL (2014)

La problemática fundamental que es recurrente en los países con alto endeudamiento como lo plantea Obstfeld y Rogoff (1996), es la conveniencia o no de declaración unilateral de su deuda o parte de ella. En esta dicotomía está por un lado, el beneficio que puede llegar a traer, liberar la presión pública presupuestaria del pago de los servicios de la deuda en general y su aprovechamiento para otros fines internos de los gobiernos; y, por el otro, la dificultad de lograr financiamiento externo luego de no haber honrado una deuda (siendo la deuda uno de los mecanismos normales para el financiamiento de obras estrategicas para el desarrollo 
de un país). Así, este documento brinda un análisis práctico a las consideraciones de de Obstfeld y Rogoff, y como la teoria suele diferir de la realidad.

\section{Descripción del contexto del problema:}

La deuda ha sido una larga historia de padecimiento y de poco beneficio, de un uso ineficiente de la misma destinada al pago de deuda corriente y no de creación de condiciones o mejoramiento para la sociedad o algún sector en particular (tal como debe ser su verdadero uso y solicitud de préstamos por parte de un estado nacional o gobiernos provinciales o locales).

El comienzo desenfrenado de la deuda se podría situar en un punto de inflexión, que casualmente fue similar en la región sudamericana: los gobiernos militares. Ecuador, bajo la bandera de un nacionalismo para todos, según Cueva Jaramillo (2005), realizó una ampliación de su deuda externa pública a través de préstamos a organismos internacionales de crédito, a fin de poder transformar su aparataje industrial hacia la agregación de valor, y de este modo por fin dejar un modelo agroexportador que había sido el modo normal de producción y crecimiento económico por aquella época; estimándose que estos factores son unas de las variables que afectan a las organizaciones sean estas públicas o privadas (Navas, Vera, \& Amen, 2018). Y a su vez, el dinero llegado del exterior se destinaría para una retrasada promesa que promovía la igualdad de clases a través de la redistribución de los ingresos en un país de grandes desigualdades; sin embargo, el dinero fue destinado para el aseguramiento del proceso militar por medio de la persecución, el miedo y la represión. El desvío de dinero del gobierno encabezado por militares golpistas, durante el periodo 19721976, a cargo del General Guillermo Rodríguez Lara, produjo un efecto contrario al determinado y justificado, al solicitar préstamos internacionales, en definitiva, mayores cantidades de dinero para el gobierno y los grupos empresariales asociados a ellos.

Desde la década del 70 hasta la etapa contemporánea del país, siguió una serie interminable de endeudamiento externo por parte de los gobiernos de turno, hasta llegar a otro hito de la deuda pública ecuatoriana: la crisis financiera de 1999 (feriado bancario). El fatídico 8 de marzo de 1999, el gobierno ecuatoriano, presidido por aquel entonces por el Dr. Jamil Mahuad Witt, decretó un feriado bancario de 24 horas (duró 5 días finalmente), paralizando todas las operaciones financieras en aquellos días, y se congelaron los depósitos durante 1 año de las cuentas que sobrepasaban los 2 millones de sucres.

Sin embargo, la crisis tuvo su origen en el gobierno del Arq. Sixto Durán Ballén y el Econ. Alberto Dahik Garzozi, promotores del neoliberalismo en el Ecuador, que con la creación de la Ley de Instituciones Financieras, se liberalizó las tasas de interés y permitió la libre circulación de capitales y el aumento de los créditos vinculados, que crecieron sin control, lo que generó especulación, agresiva devaluación del sucre (hasta aquel entonces, la moneda del Ecuador), que llegó a perder hasta el $195 \%$ de su valor, elevados e insostenibles niveles 
inflacionarios, fuga de capitales y masiva quiebra de los bancos; y, luego de desmanejos privados y públicos, el estado tuvo que asumir como propia, deuda de entidades financieras quebradas o en proceso de rescate financiero, ante la posibilidad del quiebre total del sistema financiero del país, utilizando para ello un monto cercano a 1,6 mil millones de dólares de los fondos del estado de Ecuador destinado a los bancos que quebraron (Vidal-Folch \& Del Río, 2015); la crisis financiera produjo aproximadamente un $70 \%$ del cierre de las instituciones financieras del país y las pérdidas económicas ascendieron aproximadamente a 8.000 millones de dólares. Al asumir el estado los costos de dicha, los transmitió a la población mediante algunos mecanismos, tales como la elevación del costo de los servicios y la reducción de la inversión social.

El 9 de enero del año 2000, se decreta el sistema de dolarización de la economía ecuatoriana, como única salida a su profunda crisis financiera, que consistió básicamente en que el valor de un dólar estadounidense era equivalente a 25.000 sucres en ese entonces, debiendo el estado asumir deuda en la moneda local (sucre), que luego fue transformada en la nueva moneda local (dólar estadounidense). Todo el proceso anterior se ha visto acrecentado por efectos que golpearon y aún golpean el presupuesto general del estado, deficitario por naturaleza; por el lado de los egresos, un incremento de las tasas de interés a nivel internacional y por el lado de los ingresos, la caída más pronunciada del precio del petróleo, históricamente el producto más exportado por el Ecuador (Pettiná, 2014).

En medio de todo el descontrol de la deuda, está el papel que juegan los organismos internacionales en los procesos de renegociación y reestructuración de deudas, a través del rol intervencionista en las políticas internas que aseguraran la estabilidad de los países, la continuidad de un modelo neoliberal, el flujo de dinero para el pago de las obligaciones y la continuidad de ciertos privilegios (justamente para grupos privilegiados); como estandartes de los organismos multilaterales de crédito, figuran el Fondo Monetario Internación (FMI) y el Banco Mundial (BM), que en la década de los 80’s y 90’s tuvieron un papel preponderante en las relaciones entre los acreedores y Latinoamérica. En el caso de Ecuador se debe mencionar la participación en los 80’s, en el llamado Plan Baker (iniciativa presentada en 1985 por el secretario del Tesoro estadounidense, James Baker, en la asamblea general del FMI, consistente en un programa de asistencia a las naciones más endeudadas del tercer mundo, mediante la aportación voluntaria de dinero fresco por parte de la banca privada internacional y otras agencias de asistencia multilateral), y luego, el Plan Brady (ya abordado con anterioridad). Durante todo este proceso, y luego del mismo, se empezó a observar como las clases media y baja, así como grupos de mayor vulnerabilidad, empezaron a sufrir el peso del olvido y la relegación por parte de los gobiernos de turno. Reflejos de esta situación se manifestaron en un periodo de diez años hasta la elección del Econ. Rafael Correa Delgado, como Presidente constitucional del Ecuador en noviembre de 2006, con nueve diferentes presidentes que lo antecedieron (Sánchez Arboleda, 2014). Este escenario, dejó un espacio para una nueva propuesta política que según palabras del propio Correa (2010), dejaba de 
lado la vieja política, la dirección de grupos de poder empresariales y del sector financiero; dicha situación originó el objeto de análisis del presente trabajo: el rechazo a lo considerado como una renegociación de deuda perjudicial y por lo tanto ilegítima de dos bonos: Global 2012 y Global 2030.

\section{Analizar como el objeto del caso se encontraba en los períodos previos al evento.}

Previo al desarrollo de las dificultades del caso, se determinará la situación del país en cuanto a los últimos años antes del default del 2008, basando el análisis en los datos del Banco Central del Ecuador (2010).

Alrededor del año 2006 como muestra el gráfico 1, se puede observar que el crecimiento del país desde que Correa Delgado llega al país fue positivo, con tasas del $8 \%$ en el 2004 y del $4 \%$ en el momento del default. Se considera como la peor crisis del Ecuador, la del año 1999, observándose que el "nuevo gobierno" encontró un periodo de prosperidad sobre los cuales debía actuar y con picos de crecimientos fuera de su promedio, de casi un $2 \%$.

Gráfico 1 Crecimiento del Producto Interno comparativo al Ecuador

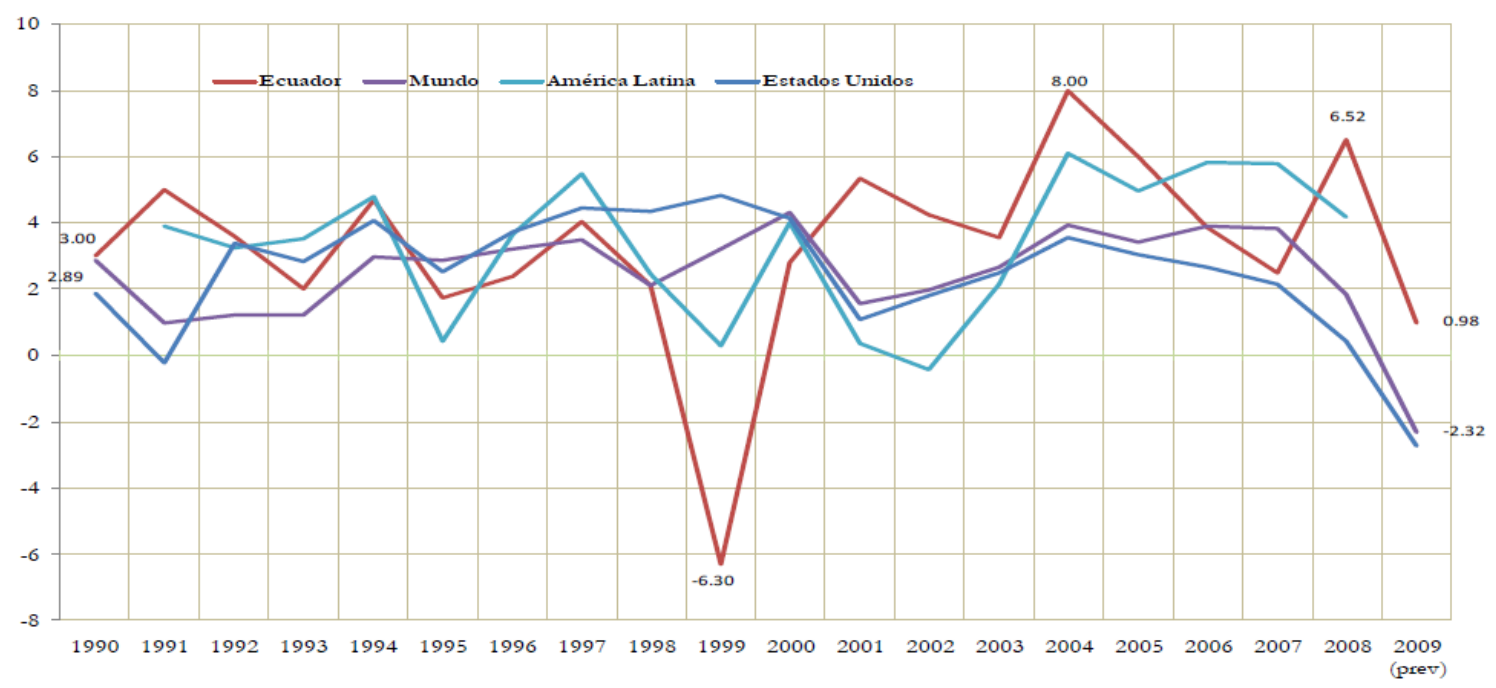

Fuente: Banco Central del Ecuador (2010)

Otro indicador que sirve como antesala de la situación del Ecuador, es el precio del barril del petróleo (primer producto exportable del Ecuador). En el gráfico 2, es claro el proceso en alza del precio del crudo ecuatoriano que muestra un ejemplo del incremento de los ingresos del país debido al alza en el precio del crudo ecuatoriano.

Gráfico 2 Comparación del precio del petróleo internacional (WTI) y el crudo de Ecuador 


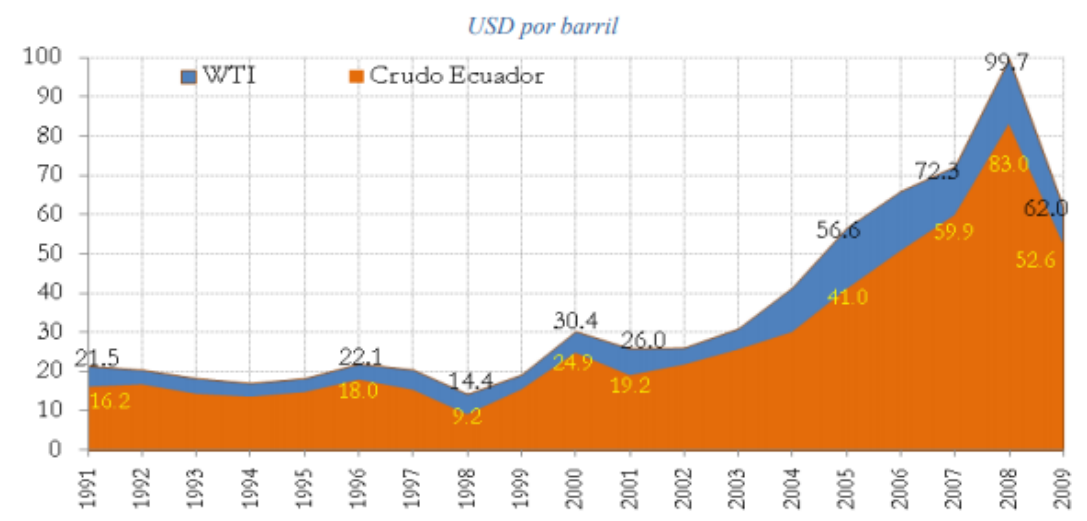

Fuente: Banco Central del Ecuador (2010)

Junto al análisis del gráfico 2, se observa el índice de intercambio (base $2000=100$ ) que muestra una comparación con y sin el petróleo, tal como lo refleja a continuación el grafico 3:

Gráfico 3 Índice de términos de intercambio 90-09

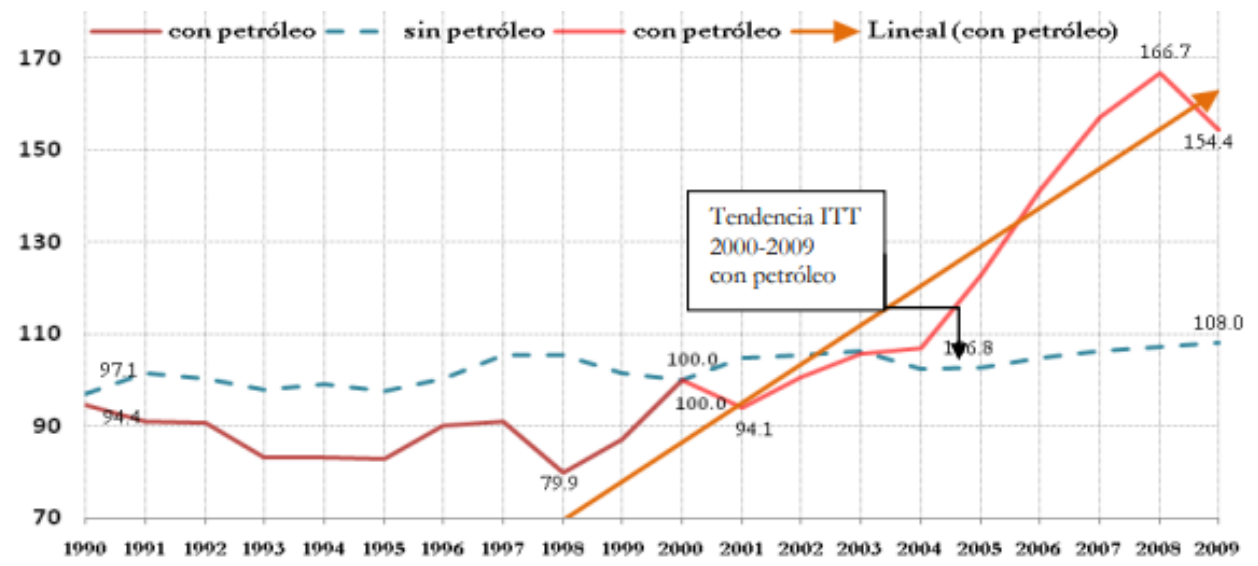

Fuente: Banco Central del Ecuador (2010)

Mientras que en el gráfico 4, se observa el crecimiento del país, en todos sus indicadores, incluso en el sector gubernamental, a partir de 1999, lo que demuestra, en definitiva, que luego del feriado bancario y posterior dolarización, todo tuvo un crecimiento (incluidas las importaciones).

Gráfico 4 Evolución de los principales componentes del PBI 90 - 09 


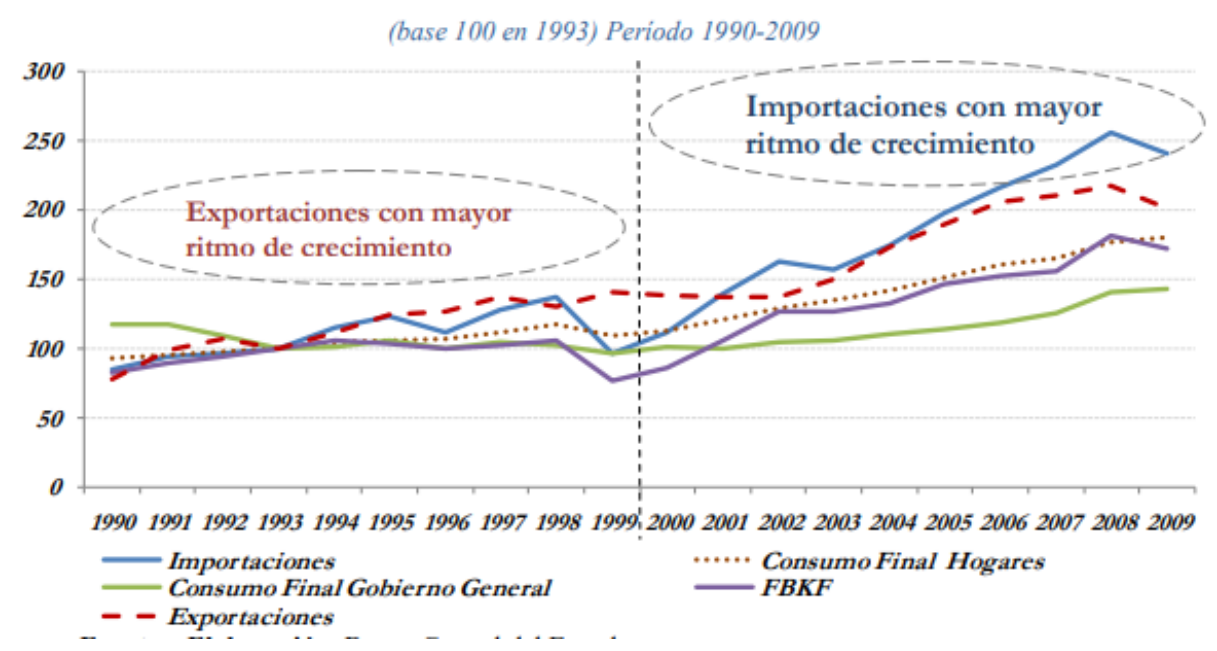

Fuente: Banco Central del Ecuador (2010)

\section{Desarrollar el problema y su resolución.}

La historia de este caso gira alrededor de la declaración unilateral de un segmento de la deuda externa del Ecuador, que fue recuperada a través de una recompra de la deuda. El gobierno ecuatoriano presentó a los poseedores de los mencionados bonos una propuesta para recomprar dichos papeles por un monto global de USD \$ 3.200 millones de dólares, utilizando una controvertida estrategia para dicha operación de recompra, favorable para algunos analistas económicos, como el Nobel de Economía Joseph Stiglitz quién señaló en 2009 que "la decisión fue beneficiosa para Ecuador; hay costos y beneficios que asumir"; y, desastrosa para otros, ya que según Wall Street "se constituía en el primer ejemplo de un país solvente que se niega a pagar su deuda externa" y de acuerdo a otro grupo de analistas económicos, esto afectó la credibilidad del país en los mercados internacionales, por esta razón subieron las tasas de interés para los bonos ecuatorianos, una vez que Ecuador volvió a los mercados internacionales en el año 2014, luego del default. El mecanismo determinó una nueva estructura de la deuda del país para el 2009, de tal forma que a mediados de año, ya se había recomprado parte de la deuda y lo que quedó fuera de la posible compra, se adquirió a través de una subasta inversa, finalizando el año con una disminución sustancial de la deuda externa del Ecuador.

Tal como muestra el gráfico 5, se observa que el canje de los bonos Brady encareció el servicio de la deuda de los bonos Global 2012 con una tasa de interés del 12\% y de los bonos Global 2030 que llegaría a los $10 \%$, en contraposición a los 4,5\% de los bonos Brady, que al ser canjeados por los bonos Global, se penalizó con un aumento de tasa de interés de más del doble y casi el triple respectivamente.

Gráfico 5 Tasas de interés de Bonos Ecuador en canje de deuda. 


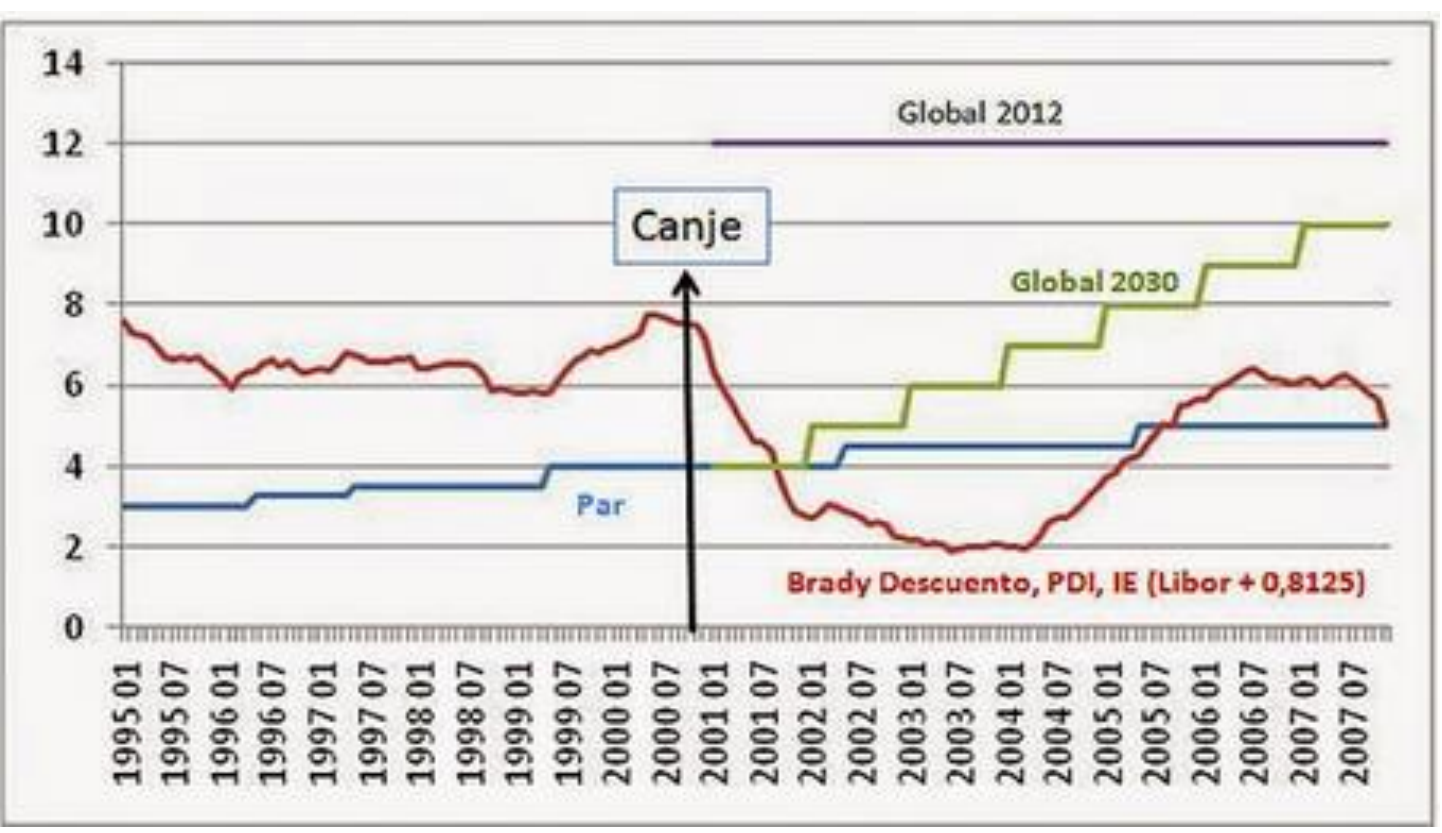

Fuente: Banco Central del Ecuador (2010)

El mecanismo final de recompra de los bonos Global 2012 y Global 2030, fue a mitad del año de 2009 y consistió en una subasta inversa como mecanismos de adquisición de la deuda que ante la declaración del no pago, hizo que la cotización del bono bajara. Ante esta situación, el gobierno determinó que antes de realizar la subasta se podía aprovechar la compra de bonos de aquellos acreedores que estaban dispuestos a vender; de este modo, el Banco del Pacifico (banco controlado por el estado ecuatoriano) comenzó la compra con valores cercanos al $20 \%$ del valor nominal de los títulos de crédito. Luego de todo este proceso, se realizó una subasta inversa, con lo que se pudo recuperar bonos de los que no pudo comprar el mencionado banco (Pacifico). Luego de ambos procesos, se terminó recuperando el 93,2\% de los bonos en disputa, con un descuento del 35\% sobre el valor nominal (Vidal-Folch \& Del Río, 2015).

El final del año 2009 muestra una gran diferencia en la deuda externa del Ecuador, con una disminución del 27\% de la deuda publica (Banco Central del Ecuador, 2010), y a su vez de acuerdo al análisis de Vidal-Folch \& Del Río (2015) "el servicio total de la deuda externa como \% del PIB se reduce del 3.5\% y 2,7\% en los años 2007 y 2008 al 1,4\%" en año posterior al default" y los intereses dan una disminución casi a la mitad en la relacion 2008 y 2010. Esto significó un alivio, dentro del constante aumento del déficit presupuestario y de cuentas corrientes debido a los valores que representaba el servicio de la deuda.

Luego de la situación acontecida, se ha podido observar un giro hacia la búsqueda de otro tipo de socios o prestamistas por parte de Ecuador, un poco más inmersos hacia una nueva realidad del mundo. Es claro que lo que pasó en el contexto ecuatoriano, antes y después de 
la llegada de Rafael Correa al poder, fue un fenómeno distinto y puso a tono al país con el nuevo orden de la economía mundial, empezándose a reconocer un nuevo participante con un gran poderío económico: China.

El claro ejemplo en Latinoamérica de este fenómeno se puede percibir en el libro de Gallagher, Irwin, y Koleski (2012) que describe unos 75 mil millones de dólares provenientes de China en el período 2005-2011. Sumado a esto, se determinó que no eran más el Banco Mundial (BM), el Fondo Monetario Internacional (FMI), o el Banco de Exportaciones e Importaciones de Estados Unidos (Eximbank), entre otros, los mayores prestadores de la región, sino que bancos chinos como el Banco de Desarrollo Chino, el Banco ICBC y el Exim Bank de China, han superado a los antiguos prestadores de la región, con compromisos diferentes a los adquiridos en el pasado, en cuanto a las garantias o colaterales que se solicitan para la aprobación de los créditos. Y, por último, la importancia de estos préstamos a la región, concentrados en Argentina, Brasil, Ecuador y Venezuela, con un aproximado del $91 \%$ del destino de estos préstamos para estos cuatro países.

El efecto antes descrito, conjuntamente con una mejor relación de gastos para el pago de servicios de la deuda, no repercutió en un presupuesto saneado que asegurara una situación de equilibrio hacia el sector de prestamistas externos e internos, sino que al contrario, si se compara la relación entre el servicio de la deuda y el gasto del sector público, que no tiene que ver con lo financiero (ambos bajo el parámetro de relación porcentual con el PBI, corriente al 2005), se puede observar como el pico de servicios de deuda llega a un 8,7\% en el 2009, luego una caída a 2,4\% en el 2010 y una casi estabilización al 3\% en 2011 y 2012; por otro lado, el gasto del Sector Publico No Financiero (SPNF) se vio incrementado en el mismo período anterior desde un valor cercano a los $33 \%$ en el 2009, a un valor que oscila en $42 \%$ en el 2012. La relación entre ellos muestra que mientras uno tendía a la baja en casi cinco puntos porcentuales (los servicios de la deuda), el otro aumenta en casi un 10\% (gasto SPNF). En definitiva, en vez de disminuir la presión en el gasto gubernamental en un casi $5 \%$ por la disminución del pago de amortización e intereses de la deuda pública, sucedió el efecto contrario, ya que aumentó el gasto del gobierno por un mayor gasto no financiero.

La deuda externa ecuatoriana, luego del proceso de disminución de la misma, continuó con su tendencia de crecimiento del endeudamiento, ahora con nuevos prestamistas, dejando de lado al FMI y BM, los cuales presionaron y condicionaron, durante largos períodos de tiempo, el modo de gobernar del país (Correa, 2010), tendiendo a partir de los últimos tiempos, a solicitar créditos a organismos como el Banco Interamericano de Desarrollo (BID) y la Corporación Andina de Fomento $(\mathrm{CAF})$, organismos con un enfoque más regional y como tal, con menos presiones a la intervención interna (o alineada a la política interna y externa del gobierno). Se comenzó también un proceso de adquisición de deuda con el gobierno de China, y otros acuerdos bilaterales, considerándose el trato entre ambos países, como el más relacional de todos en el sentido de la deuda. Según Vidal-Folch \& Del Río 
(2015) en el periodo post-default, de 2008 a 2012, se representa esta relación con una proporción de casi el $60 \%$, si se compara el total de la deuda con el prestamista (China). Esta correlación fue aún más profunda, a partir de la venta anticipada de petróleo por parte del gobierno ecuatoriano al gobierno chino, con un proceso similiar al tratamiento de una deuda, sobre todo si se concluye que por ésta venta anticipada se están pagando intereses actualmente; asimismo, se halla dentro del contexto de la economía ecuatoriana, financiamiento de bancos chinos en hidroeléctricas o proyectos petroleros, con el aseguramiento del pago a traves de las mismas obras materiales y/o porcentajes de intervención de empresas chinas, o en la mayoría de los casos, adquisición de materiales de esa procedencia.

Otra característica de la deuda post-reestructuración, fue que comenzó nuevamente un proceso de endeudamiento desde el sector público, pero con la característica diferencial de utilizar al mercado local para la colocación de los denominados Certificados de Tesorería (CETES), que no son otra cosa que los valores emitidos por el Gobierno Central a través del Ministerio de Economía y Finanzas para captar recursos a corto plazo, usándose en calidad de dación de pago, de obligaciones que mantenía el estado ecuatoriano con entidades públicas y privadas, como municipios y universidades, por ejemplo; sin embargo de aquello, el Banco Central del Ecuador (BCE) es el segundo tenedor de papeles del Estado, luego del Instituto Ecuatoriano de Seguridad Social (IESS), entidades que posteriormente canjearon CETES por bonos internos, convirtiéndose esos dos organismos en las mayores tenedoras de papeles internos del país. Es notorio dentro de este proceso de emisión y colocación de bonos internos, el protagonismo de las instituciones públicas, y a manera de ejemplo, en el caso del IESS, con la adquisición de más de 1000 millones de dólares para el 2009 (Banco Central del Ecuador, 2010). El endeudamiento ha llegado a valores tales, que para el 2012 la deuda pública interna representaba el $42 \%$ de la deuda total del país (Vidal Forch, 2014).

\section{Conclusiones.}

- La salida de un proceso de endeudamiento y re-endeudamiento del Ecuador ha sido un proceso que impactó positivamente en el país, ya que luego de la declaración de default en forma unilateral, debería haber sufrido penalidades de los prestamistas internacionales.

- La particularidad del rescate de los bonos Global 2012 y Global 2030 está dado por el mecanismo de adquisición de deuda. Ante el no pago de aquellas obligaciones externas contraídas, el mercado comenzó el proceso de venta rápido de los bonos con una gran caída de sus valores, razón por la que el gobierno reaccionó rápidamente, utilizando primeramente el mecanismo de recompra a través de un banco que pertenece al estado y luego con el rescate de los restantes bonos a través de una subasta inversa. Con esto, se llegó a rescatar cerca del 93,2\% de ambos bonos. 
- La lección aprendida no sólo abarca enseñanzas respecto del manejo financiero del proceso de rescate, sino también en el ámbito de la gestión, sobre todo en lo que respecta al modo de dirigir una estrategia de presión ante una deuda considerada como ilegítima. Implícitamente, la lección principal es no cometer los errores del pasado, o sea en este caso, no endeudarse equivocadamente para no volver a poner presión sobre el Presupuesto General del Estado (PGE); en el desarrollo del caso se pudo demostrar que lo que aconteció fue que se incrementó la deuda externa en el mediano plazo, con la diferencia de que eran otros los prestamistas por aquel entonces.

\section{Referencias bibliográficas.}

Astorga, A. (2003). La sostenibilidad de la deuda pública: el caso del Ecuador. SERIES seminarios $y \quad$ conferencias, 28, 179-206. Obtenido de https://repositorio.cepal.org/bitstream/handle/11362/6575/S038507_es.pdf?sequenc $\mathrm{e}=1$

Banco Central del Ecuador. (2010). Boletín de Información Estadístico Mensual: Abril 2010. Quito: Banco Central del Ecuador.

Banco Central del Ecuador. (2010). La Economía Ecuatoriana: Luego de 10 años de dolarización. Quito: Banco Central del Ecuador. Obtenido de https://contenido.bce.fin.ec/documentos/PublicacionesNotas/Notas/Dolarizacion/Do larizacion10anios.pdf

CEPAL. (2014). La crisis latinoamericana de la deuda desde la perspectiva histórica. CEPAL. doi:9789212211237

Correa, R. (2010). Ecuador: de Banana Republic a No República. Bogotá: Random House Mondadori.

Cueva Jaramillo, J. (2005). Pobreza y Deduda Externa. Universitas, Revista de Ciencias Sociales $y \quad$ Humanas(2), 127-138. Obtenido de http://www.redalyc.org/articulo.oa?id=476150821008

Fernandez, G. (1999). Análisis empirico de la sostenibilidad externa: el caso del Ecuador. Nota Técnica $N^{\circ}$ 56. Quito: Banco Central del Ecuador.

Gallagher, K., Irwin, A., \& Koleski, K. (2012). The new banks in town: chinese finance in Latin America. Washington D.C.: Inter-American Dialogue.

Navas, W. I., Vera, C. A., \& Amen, C. R. (2018). Adminsitracion del cambio organizacional en las empresas familiares para la implementacion de la responsabilidad social empresarial. Revista Publicando, 5(15), 1344-1364. 
Obstfeld, M., \& Rogoff, K. (1996). Fundations of intternational macroeconomics. Cambridge: MIT Press.

Pettiná, V. (2014). Historia mínima de la deuda externa de Latinoamérica . El Colegio de México, 1915-1919. doi:978-607-462-640-7

Rodriguez, B. R. (2008). Quince minutos de fama financiera: la historia de Marc A. Hélie el "hombre que le quebró al Ecuador". Foro Revista de Derecho (10), 191-196. Obtenido de http://revistas.uasb.edu.ec/index.php/foro/article/view/355/352

Sánchez Arboleda, J. E. (Abril de 2014). La estabiliad finaciera en el Ecuador periodo 20082013. Guayaquil, Guayas, Ecuador: Universidad de Guayaquil.

Valencia, A. (31 de Diciembre de 2008). Reuters. Recuperado el 16 de Abril de 2018, de Reuters: https://ta.reuters.com/article/businessNews/idLTASIE4BU0U420081231

Vidal Forch, L. (2014). La economía política del default ecuatoriano. XIV Joranda de economía critica (págs. 140-167). Barcelona: Universidad de Valladolid. Obtenido de

https://s3.amazonaws.com/academia.edu.documents/38142315/Articulo_JEC.pdf?A WSAccessKeyId=AKIAIWOWYYGZ2Y53UL3A\&Expires=1523631410\&Signatu $\mathrm{re}=1 \% 2 \mathrm{FtLFDWax} 9 \mathrm{WbIFWP} \% 2 \mathrm{BAKEd} 8 \mathrm{khERo} \% 3 \mathrm{D} \&$ response-contentdisposition=inline\%3B\%20filename\%3DLa_Economia_Politica_del_Defa

Vidal-Folch, L., \& Del Río, A. (2015). El Default como impulso hacia una política económico heterodoxa. Una aproximación a los casos de Argentina y Ecuador. Revista de Economía Crítica(19), 100-121. Obtenido de http://www.revistaeconomiacritica.org/sites/default/files/revistas/Revista_Economia _Critica_19.pdf\#page $=100$

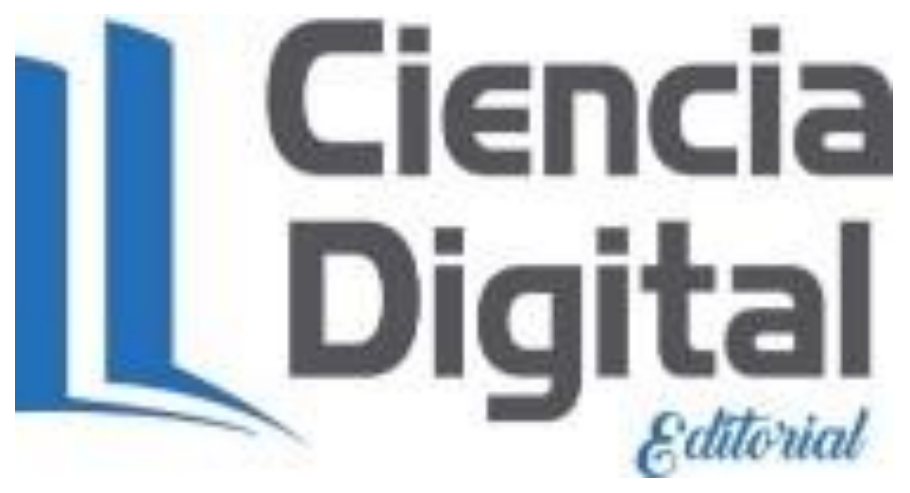


Para citar el artículo indexado.

Rodríguez G., Loor H., Navas W. (2019) Caso de estudio: el default del Ecuador 20082009. Revista electrónica Ciencia Digital 3(1), 481-494. Recuperado desde: http://cienciadigital.org/revistacienciadigital2/index.php/CienciaDigital/article/view/350/77 $\underline{1}$

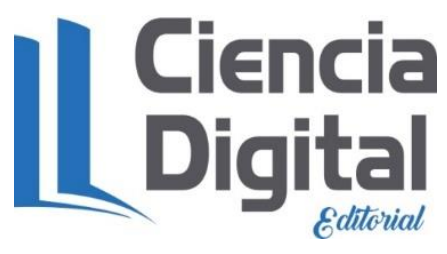

El artículo que se publica es de exclusiva responsabilidad de los autores y no necesariamente reflejan el pensamiento de la Revista Ciencia Digital.

El artículo queda en propiedad de la revista y, por tanto, su publicación parcial y/o total en otro medio tiene que ser autorizado por el director de la Revista Ciencia Digital.
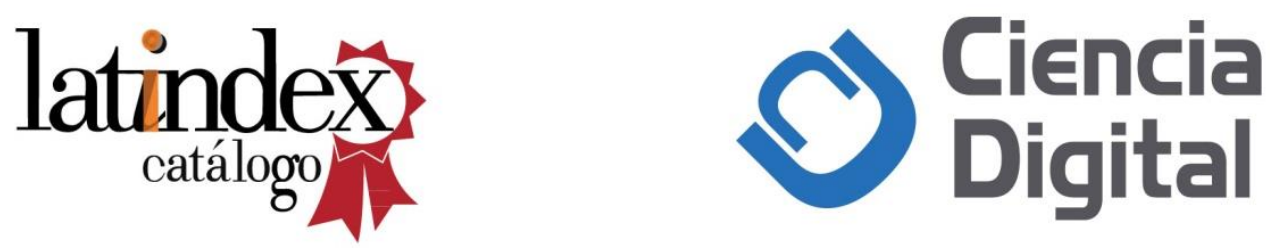